\title{
Comparison of the Efficiencies of Ofloxacin Delivered in Different Forms (Conventional, Nanoemulsion and Nanoparticles) in the Treatment of Acute Diffuse Otitis Externa
}

\author{
TAREK E.ABOU-SHARAF, M.D.*; WEDAD S. SAKRAN, M.D.**; SHEREN M. SAMEH, M.D.*** and \\ YOSRA T. EMAM, M.Sc.*** \\ The Department of ORL-H \& N Surgery Shebin El-Kom Teaching Hospital* and The Department of Pharmaceutics, \\ Faculty of Pharmacy, Helwan** and of October*** Universities
}

\begin{abstract}
Background: Acute diffuse otitis externa is usually painful and annoying to the patient. It is an acute inflammation of the external auditory canal, auricle or both. Topical antibiotic preparations are the treatment of choice in uncomplicated cases. With the introduction of nanotechnology in the development of antibiotics, new horizons were opened up for the treatment of acute diffuse otitis externa.
\end{abstract}

Aim of Study: The objective of the present study is to compare the efficiencies of ofloxacin delivered in different forms (conventional, nanoemulsion and nanoparticles) in the treatment of acute diffuse otitis externa.

Patients and Methods: In the present study, we compared the efficiencies of ofloxacin delivered in different forms (conventional, nanoemulsion and nanoparticles) in cases with acute diffuse otitis externa. 40 patients with moderate degree of acute diffuse otitis externa were included in this study. The patients were classified into 4 groups, 10 patients in each group. A different form of ofloxacin was used in each group.

Results: The present study showed that: (1) There was no difference in cure rate between cases treated by nanoemulsion form of ofloxacin and cases treated by nanoparticles form of ofloxacin. (2) Both of the nanoemulsion and nanoparticles are more effective than the conventional form (when used in the same concentration). (3) On trial of low concentration of the nanoemulsion form, no difference in cure rate from the conventional form was noted.

Conclusion: Nanopreparations of ofloxacin are more effective than the conventional form in management of cases of acute diffuse otitis externa.

Key Words: Otitis externa - Ofloxacin - Nanoparticles Nanoemulsion.

Correspondence to: Dr. Tarek Emam Abou-Sharaf, E-Mail: tarekemam14@yahoo.com

\section{Introduction}

BOTH anatomically and functionally, the ear is divided into three parts: The external ear, the middle ear and the inner ear. The external ear is that portion of the ear external to the tympanic membrane. It consists of the auricle and the external auditory canal [1] Fig. (1).

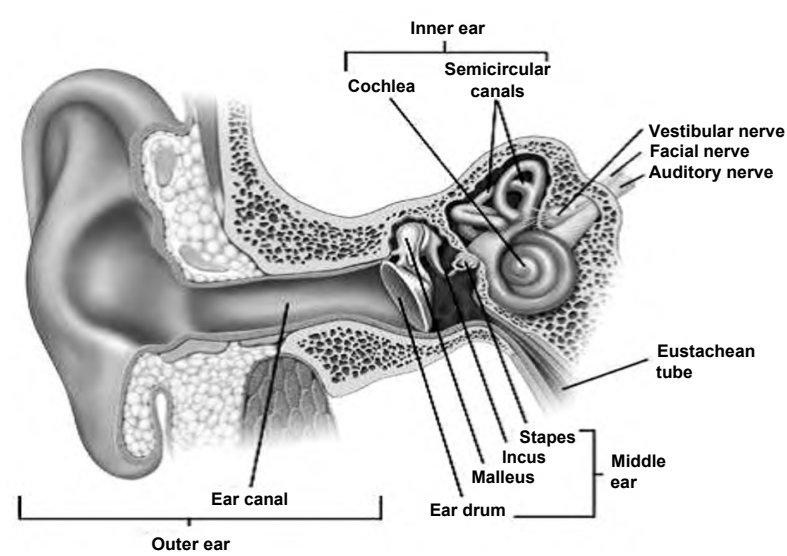

Fig. (1): Anatomy of the ear.

Otitis externa is an inflammation or infection of the external auditory canal, the auricle or both [2-4] . It is a common disease that can be found in all age groups [5]. It is one of the most common infections encountered by clinicians all over the world [6]. It occurs in 4 of every 1000 people annually $[7,8]$. The infection is more prevalent in hot and humid conditions $[5,8]$.

Otitis externa usually represents an acute bacterial infection of the skin of the ear canal-most commonly attributable to pseudomonas aeruginosa or staphylococcus aureus [9], but can also be caused by other bacteria, viruses or a fungal infection [6] 
Several factors can contribute to external auditory canal infection and the development of otitis externa, including the following [8]

- Absence of cerumen.

- High humidity.

- Increased temperature.

- Local trauma (e.g. use of cotton swabs or hearing aids).

Otitis externa occurs more often in summer time, when swimming is more common $[\mathbf{5 , 8 ]}$. It is also common in tropical areas due to high temperature $\&$ humidity [10]. Individuals with allergic conditions are also at significantly higher risk of otitis externa $[\mathbf{7 , 1 1}]$

According to the American Academy of Otolaryngology-Head and Neck Surgery (2014), otitis externa is classified as follows [6]

1- Acute diffuse otitis externa (the most common form).

2- Acute localized otitis externa.

3- Chronic otitis externa.

4- Eczematous otitis externa.

5- Necrotizing otitis externa.

6- Otomycosis.

Most cases of otitis externa resolve without difficulty. The majority of patients improve within 48-72 hours of treatment. Otitis externa usually resolves fully in 7 days. However, if left untreated, the infection can invade the deeper adjacent structures causing lymphadenitis or cellulitis of the face and neck. In immunocompromised patients (e.g. diabetics), the infection may progress to necrotizing otitis externa which is a serious condition with high morbidity and mortality rate [6].

Rosenfeld et al., (2014) have summarized the clinical presentation of patients with acute otitis externa. These patients may complain of the following:

- Otalgia (ranging from mild to severe, typically progressing over 1-2 days).

- Hearing loss and ear fullness.

- Tinnitus.

- Fever (occasionally).

- Itching (especially in fungal otitis externa or chronic otitis externa).

- Discharge (initially the discharge is clear and odorless but quickly becomes purulent and foul smelling).
Usually there is a history of preceding ear trauma or entrance of water in the ear canal (e.g. swimming). These symptoms are usually unilateral (90\% of cases).

On examination, there is pain upon palpation of the tragus or application of traction to the pinna. Examination also reveals erythema, edema and narrowing of the external auditory canal. A serous or purulent discharge may be noted. Conductive hearing loss may be evident. In sever forms of otitis externa, cellulitis of the face or neck or lymphadenopathy may occur. The tympanic membrane may be difficult to visualize and may be mild congested [6].

Primary treatment of acute otitis externa involves management of pain, removal of debris from the external auditory canal, administration of topical medications to control edema and infection and avoidance of contributing factors. Most cases of acute otitis externa respond well to topical treatment. Antibiotic drops with or without a corticosteroid are the mainstays of therapy [12]. In a review of therapy for otitis externa, Roland et al. (2008) [13] demonstrated that the combination of oral antibiotics with otic antibiotic solutions hasn't been shown to improve treatment success rate. Moreover, systemic antibiotics may be accompanied by several adverse effects. Systemic antibiotics are generally reserved for patients with infection extending outside the external auditory canal (lymphadenitis or cellulitis of the face and neck).

\section{Patients and Methods}

In the present study, the efficiencies of ofloxacin delivered in different forms (conventional, nanoemulsion and nanoparticles) in treatment of cases with infections to the external auditory canal were compared. The study comprises both the clinical response and bacterial eradication.

The study was done at Helwan University, October 6 University and Shebin El-Kom Teaching Hospital during December 2018. This study included 40 patients with moderate degree of diffuse otitis externa. The patients were classified into four groups; 10 patients in each group. A different form of ofloxacin was used in each group (Table $1)$.

In selection of the cases, the following were the inclusion criteria:

- Patients are adult above 18 years and non-diabetic. 
- Patients are non-allergic to the drug used (ofloxacin) or any other quinolone.

- Female patients are not pregnant and non-lactating.

- Patients should be evaluated before starting treatment to exclude any underlying condition such as tympanic membrane perforation, tumor or foreign body.

Patients who fulfilled these criteria were subjected to the following:

- History talking.

- Examination (general and local).

- Ear swab (for microbial culture and sensitivity).

- Application of the different forms of ofloxacin (after simple cleaning and drying of the external auditory canal).

Application method: The application was done by the doctor himself (not by the patient). 10 drops $(0.5 \mathrm{ml})$ of ofloxacin were used into the affected ear once daily. In acute phase, topical ofloxacin was applied in a wick. After the acute phase, topical ofloxacin was continued as ear drops.

The wick has the following benefits:

- Removal of exudate by capillary action.

- The close and prolonged application of the drug.

- A barrier to prevent scratching by the patient.

\section{Evaluation method:}

Evaluation of the patient response to treatment was performed (over 7 days) by:

1- Clinical improvement.

2- Bacteriological examination.

N.B.:

1- This study had approval of the Ethical Committee.

2- We explained to each patient the purpose of this study and the forms of the drug used. Convinced answers were given about all questions from the patients. An informed consent was obtained.

3- Topical ofloxacin nanopreparations, including nanoparticles and nanoemulsions (with different concentrations), were successfully developed and characterized by various methods by the staff members of:

I- Pharmaceutical Department, Faculty of Pharmacy, Helwan University.

II- Pharmaceutical Department, Faculty of Pharmacy, October 6 University.
Table (1): Subdivision of patients into four groups.

\begin{tabular}{|c|c|}
\hline Group & Form of ofloxacin used \\
\hline A & - Conventional form of ofloxacin $(0.3 \%)$ \\
\hline $\mathrm{B}$ & $\begin{array}{l}\text { - Ofloxacin nanoemulsion of the same } \\
\text { concentration as the conventional form } \\
(0.3 \%) \text {. }\end{array}$ \\
\hline $\mathrm{C}$ & $\begin{array}{l}\text { - Ofloxacin nanoemulsion of a lower con- } \\
\text { centration than the conventional form } \\
(0.2 \%) \text {. }\end{array}$ \\
\hline $\mathrm{D}$ & $\begin{array}{l}\text { - Ofloxacin nanoparticles of the same con- } \\
\text { centration as the conventional form } \\
(0.3 \%) \text {. }\end{array}$ \\
\hline
\end{tabular}

\section{Results}

Analysis of the results in this study revealed the following:

- The ages of the patients ranged from 18 to 54 years.

- The onset of acute otitis externa ranged from 1 to 7 days.

- The patients were classified into four groups, 10 patients in each group. A different form of ofloxacin was used in each group (Table 1).

- The overall cure rate was $70 \%$.

- The clinical cure rate in the four groups was (Table 2):

- $60 \%$ in Group A.

$-80 \%$ in Group B.

- $60 \%$ in Group C.

$-80 \%$ in Group D.

Table (2): Clinical cure rate

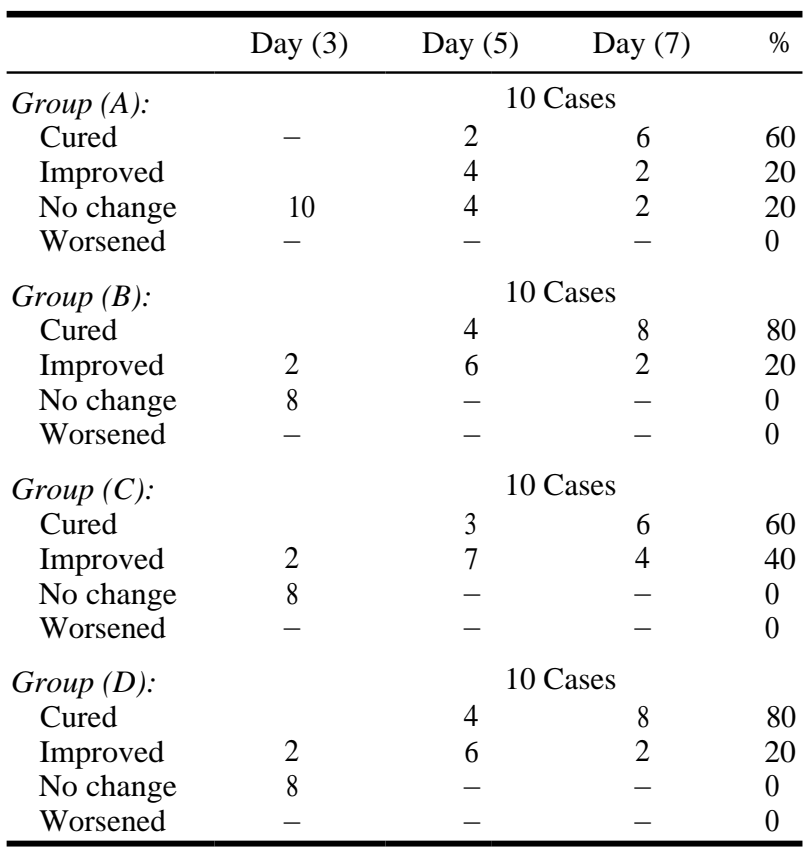


- The bacteriological eradication in the four groups was (Table 3):

- 70\% in Group A.

$-90 \%$ in Group B.

$-70 \%$ in Group C.

- $90 \%$ in Group D.

Table (3): Bacteriological eradication.

\begin{tabular}{lccc}
\hline Group & $\begin{array}{c}+\mathrm{ve} \\
\text { culture }\end{array}$ & $\begin{array}{c}-\mathrm{ve} \\
\text { culture }\end{array}$ & Rate of bacteriological eradication \\
\hline $\mathrm{A}$ & 3 & 7 & $70 \%$ \\
$\mathrm{~B}$ & 1 & 9 & $90 \%$ \\
$\mathrm{C}$ & 3 & 7 & $70 \%$ \\
$\mathrm{D}$ & 1 & 9 & $90 \%$ \\
\hline N.B.: & \multicolumn{4}{l}{} \\
+ve culture: Presence of microorganisms, \\
-ve culture : Absence of microorganisms = Bacteriological eradication.
\end{tabular}

- The overall tolerability in the four groups was excellent (Table 4).

Table (4): Overall tolerability.

\begin{tabular}{cc}
\hline & 10 Cases \\
\hline Group $(A)$ : & 10 \\
Excellent & - \\
Fair & - \\
Poor & \\
Group $(B):$ & 10 \\
Excellent & - \\
Fair & - \\
Poor & \\
Group $(C):$ & 10 \\
Excellent & - \\
Fair & - \\
Poor & \\
Group $(D):$ & 10 \\
Excellent & - \\
Fair & - \\
Poor &
\end{tabular}

\section{Discussion}

Infections of the external auditory canal are usually painful and annoying to the patient. It is a common condition and affects between $5 \%$ to $20 \%$ of the patients attending ENT clinics [14]. An estimated $10 \%$ of people develop external otitis during their life time [15].

Otitis externa is typically a localized process that can be easily controlled with topical agents. If otitis externa is not optimally treated, especially inimmunocompromised patients, the infection can spread to the surrounding tissues and may even become a life-threatening condition [16] .
Acute otitis externa as discussed in this study is defined as diffuse inflammation of the external ear canal which is almost exclusively a bacterial infection. The target patient is aged 18 years or more.

A variety of types and forms (systemic and topical) of antibiotics have been developed in an attempt to manage acute diffuse otitis externa. Systemic antibiotics may increase the risks of adverse effects. They may cause generation of resistant strains of organisms. They also increase time to clinical cure and don't improve outcomes compared with topical antibiotics alone [17]. So there was always a desire to avoid systemic antibiotics and depend only on local forms.

Ofloxacin otic solution is a common topical formulation that has a wide spectrum of activity against most common ear pathogens [18]. It is the only topical agent to be labeled by the Food and Drug Adminstration for use when the tympanic membrane is perforated and should be used when the status of the tympanic membrane cannot be determined [2].

The design and development of new drug delivery system with the intention of enhancing the efficacy of the existing drug is an ongoing process in pharmaceutical research. One of the most important techniques for enhancement of permeation of drugs is the use of nanopreparations.

It has been suggested that nanopreparations may dissolve the ordered structure of the stratum corneum lipid leading to the loss of the barrier properties of the skin, i.e. breaching the skin [19]. Nanopreparations have the ability to deliver larger amounts of topically applied agents into the skin than other traditional vehicles such as lotions or creams [20]

The external auditory canal is lined by skin. Thus the topical use of nanopreparation forms of ofloxacin is assumed to have favorable effects than the conventional forms in treatment of acute diffuse otitis externa.

With the introduction of nanotechnology in the development of antibiotics' formulations, new horizons were opened up for the treatment of acute diffuse otitis externa. Subramanian et al., (2012) [21] presented a basic study for the use of ofloxacin nanoparticles with improvement of the therapeutic efficacy of ofloxacin. Further contributions were made by Marslin et al., (2015) [22] . They concluded that nano-formulations improved antibacterial activity against all the tested human bacterial 
pathogens including Staphylococcus aureus and Pseudomonas aeruginosa.

Acute otitis externa can generally be classified into two main groups: (1) Localized otitis externa (frunculosis) (2) Diffuse otitis externa. The diffuse group is further subdivided-according to the degree of inflammation- into three forms; mild, moderate and severe [23].

In this study, we selected moderate cases as the line of treatment of this group of patients is topical antibiotic. Mild cases usually do not need antibiotics (systemic or local) in their treatment. Severe cases usually need systemic antibiotic in their treatment.

In the current study, there was no difference in cure rate between cases treated by nanoemulsion form of $0.3 \%$ ofloxacin (Group B) and cases treated by nanoparticlesform of $0.3 \%$ ofloxacin (Group D). The present study showed that both of nanoemulsion and nanoparticles forms of ofloxacin are more effective than the conventional form in treatment of diffuse otitis externa (when used in the same concentration). On trial of low concentration of the nanoemulsion form (Group C), no difference in cure rate was noted from the conventional form (Group A).

In the current study, we also noticed the following:

1- Faster improvement of otitis externa with all tested nanopreparations (from the 3 rd day).

2- Two of the cases did not respond to the topical use of ofloxacin. These cases were evaluated clinically as the disease spread beyond the external auditory canal. Systemic antibiotics (Quinolones) were added to the list of treatments and clinical response was achieved after few days. This occurred with the conventional ofloxacin (Oflox ${ }^{\circledR}$ drops) only and did not occur with any of the prepared nanopreparations.

\section{Conclusion:}

Nanopreparations of Ofloxacin are more effective than the conventional form in management of cases of acute otitis externa. As bacteriological eradication is more with the nanopreparations, it is expected that the incidence of recurrence would be less. The relatively high incidence of acute diffuse otitis externa and the associated annoying symptoms make it an important condition for the use of an up to date evidence-based treatment.

\section{References}

1- AUSTIN D.F.: Diseases of the Nose, Throat and Ear; ed. Ballenger J.J., 13 th ed., P. 877-923, 1985.
2- ROSENFELD R.M., BROWN L., CANNON C.R., DOLOR R.J., GANIATS T.G., HANNLEY M. and STINNETT S.S.: Clinical practice guideline: Acute otitisexterna. Otolaryngology-Head and Neck Surgery, 134 (4), S4S23, 2006 .

3- BOJRAB D.I., BRUDERLY T. and ABDULRAZZAK Y.: Otitis externa. Otolaryngologic Clinics of North America, 29 (5): 761-82, 1996

4- CANTOR R.M.: Otitis externa and otitis media. A new look at old problems. Emerg. Med. Clin. North. Am., 13 (2): 445-55, 1995.

5- ROWLANDS S., DEVALIA H., SMITH C., HUBBARD R. and DEAN A.: Otitis externa in UK general practice: A survey using the UK General Practice Research Database. Br. J. Gen. Pract., 51 (468): 533-8, 2001.

6- ROSENFELD R.M., SCHWARTZ S.R., CANNON C.R., ROLAND P.S., SIMON G.R., KUMAR K.A. and ROBERTSON P.J.: Clinical practice guideline: Acute otitis externa. Otolaryngology-Head and Neck Surgery, 150 (1): 1-24, 2014.

7- OSGUTHORPE J.D. and NIELSEN D.R.: Otitis externa Review and clinical update. Am. Fam. Physician., 74 (9): 1510-6, 2006.

8- HOLTEN K.B. and GICK J.: Management of the patient with otitis externa. Journal of Family Practice, 50 (4): 353-60, 2001.

9- CLARK W.B., BROOK I., BIANKI D. and THOMPSON D.H.: Microbiology of otitis externa. Otolaryngology Head and Neck Surgery, 116 (1): 23-5, 1997.

10- HUGHES E. and LEE J.H.: Otitis externa. Pediatr. Rev., 22 (6): 191-7, 2001.

11- RUSSELL J.D., DONNELLY M., MCSHANE D.P., ALUN-JONES T. and WALSH M.: What causes acute otitis externa? J. Laryngol. Otol., 107 (10): 898-901, 1993.

12- WALL G.M., STROMAN D.W., ROLAND P.S. and DOHAR J.: Ciprofloxacin 0.3\%/dexamethasone $0.1 \%$ sterile otic suspension for the topical treatment of ear infections: A review of the literature. Pediatr. Infect. Dis. J., 28 (2): 141-4, 2009.

13- ROLAND P.S., BELCHER B.P., BETTIS R., MAKABALE R.L., CONROY P.J. and WALL G.M.: A single topical agent is clinically equivalent to the combination of topical and oral antibiotic treatment for otitis externa. American Journal of Otolaryngology, 29 (4): 255-61, 2008.

14- HAWKE M., WONG J. and KRAJDEN S.: Clinical and microbiological features of otitis externa. The Journal of Otolaryngology, 13 (5): 289-95, 1984.

15- RAZA S.A., DENHOLM S.W. and WONG J.C.: An audit of the management of acute otitis externa in an ENT casualty clinic. The Journal of Laryngology \& Otology, 109 (2): 130-3, 1995.

16- SANDER R.: Otitis externa: A practical guide to treatment and prevention. American family physician, 63 (5): 927 36, 2001.

17- ROLAND P.S. and STROMAN D.W.: Microbiology of acute otitis externa. The Laryngoscope, 112 (7): 1166$77,2002$. 
18- SIMPSON K.L. and MARKHAM A.: Ofloxacin otic solution: A reviewof its use in the management of ear infections. Drugs, 58 (3): 509-31, 1999.

19- BADAWI A.A., NOUR S.A., SAKRAN W.S. and ELMANCY S.M.S.: Preparation and evaluation of microemulsion systems containing salicylic acid. AAPS. Pharm. Sci. Tech., 10 (4): 1081-4, 2009.

20- DERLE D.V., SAGAR B.S.H. and PIMPALE S.: Microemulsion as a vehicle for transdermal permeation of nimesulide. Indian Journal of Pharmaceutical. Sciences, 68 (5): 622-5, 2006.

21- SUBRAMANIAN L., GANESAN V., VENKATESHAN
N. and SOLAIRAJ P.: Design, formulation and evaluation of ofloxacin nanoparticles. International Journal of Biological and Pharmaceutical. Research, 3 (5): 659-62, 2012.

22- MARSLIN G., REVINA A. M., KHANDELWAL V.K.M., BALAKUMAR K., SHEEBA C.J. and FRANKLIN G.: PEGylated ofloxacin nanoparticles renderstrong antibacterial activity against many clinically important human pathogens. Colloids and Surfaces B: Biointerfaces, 132: 62-70, 2015.

23- SENTURIA B.H., MARCUS M.D. and LUCENTE F.E. Diseases of the External Ear. ${ }^{\text {nd }}$ Ed. New York: Grune \& Stratton, 1980.

\section{مقارنة تأثير الأوفلوكساسين بأشكاله المختلفة (الشكل التقليدى،

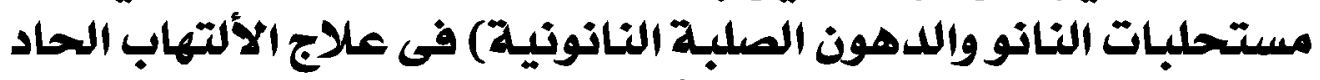 المنتشر للأذن الخارجية النونية}

تتقسم الأذن من الناحية التشريحية والوظيفية إلى ثلاث أجزاء: الأنن الخارجية وتتكن من قناة الأذن وصيوان الأنن، الأنن الوسطى، والأذن الداخلية.

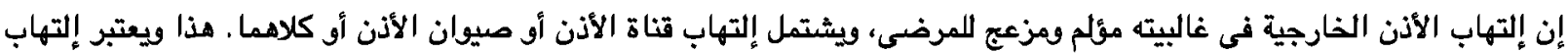

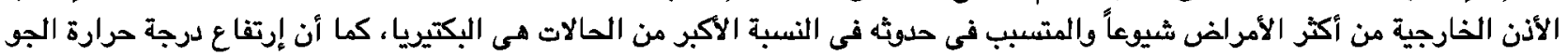

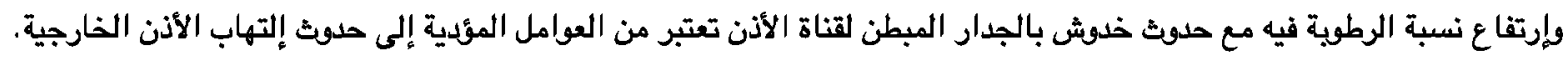

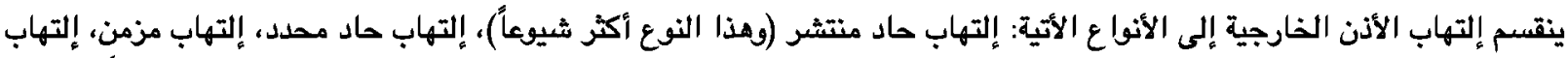

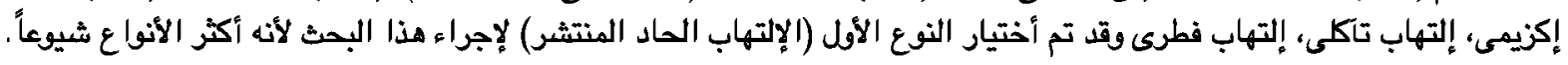

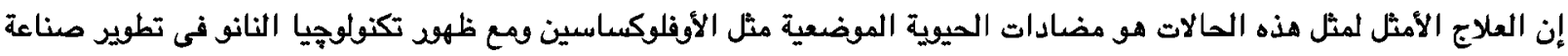

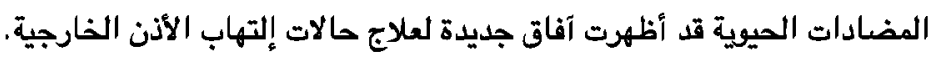

وتهدف هذه الدراسة إلى مقارنة كفاءة الأوفلوكساسين بأثكاله المختلفة (النوع التقليدى والأنقاع المتطودة بتكنولوهيا النانو) فى علاج الته

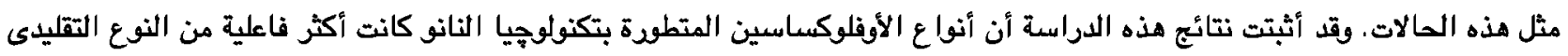

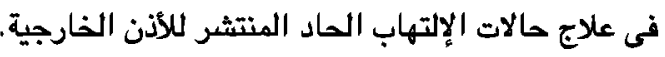

